\title{
INVESTIGATION INTO BACKGROUND LEVELS OF SMALL ORGANIC SAMPLES AT THE NERC RADIOCARBON LABORATORY
}

\author{
Tanya Ertunç ${ }^{1,2} \bullet$ Sheng $\mathrm{Xu}^{3} \bullet$ Charlotte L Bryant ${ }^{1} \bullet$ Margaret Currie $^{1} \bullet$ Stewart P H T Freeman $^{3} \bullet$ \\ Colin Maden $^{3} \cdot$ Callum Murray ${ }^{1}$
}

\begin{abstract}
Recent progress in preparation/combustion of submilligram organic samples at our laboratories is presented. Routine methods had to be modified/refined to achieve acceptable and consistent procedural blanks for organic samples smaller than $1000 \mu \mathrm{g} \mathrm{C}$. A description of the process leading to a modified combustion method for smaller organic samples is given in detail. In addition to analyzing different background materials, the influence of different chemical reagents on the overall radiocarbon background level was investigated, such as carbon contamination arising from copper oxide of different purities and from different suppliers. Using the modified combustion method, small amounts of background materials and known-age standard IAEA-C5 were individually combusted to $\mathrm{CO}_{2}$. Below $1000 \mu \mathrm{g} \mathrm{C}$, organic background levels follow an inverse mass dependency when combusted with the modified method, increasing from $0.13 \pm 0.05$ pMC up to $1.20 \pm 0.04$ $\mathrm{pMC}$ for $80 \mu \mathrm{g} \mathrm{C}$. Results for a given carbon mass were lower for combustion of etched Iceland spar calcite mineral, indicating that part of the observed background of bituminous coal was probably introduced by handling the material in atmosphere prior to combustion. Using the modified combustion method, the background-corrected activity of IAEA-C5 agreed to within $2 \sigma$ of the consensus value of $23.05 \mathrm{pMC}$ down to a sample mass of $55 \mu \mathrm{g} \mathrm{C}$.
\end{abstract}

\section{INTRODUCTION}

As part of a wider objective to determine the minimum size of inorganic and organic samples that could reliably be analyzed as graphite, we have focused on the improvement of the laboratory's procedural blank for organic samples. We describe a series of experiments to assess and differentiate background contamination arising from sample preparation. We have previously characterized a new $\mathrm{CO}_{2}$ preparation and graphitization line processing small samples $(<500 \mu \mathrm{g} \mathrm{C})$. This was achieved by identifying the optimum iron catalyst and system background, and investigating the possibility of isotopic fractionation during graphitization and accelerator mass spectrometry (AMS) measurement (Ertunç et al. 2005). For inorganic samples, a satisfactory low and stable background value of $0.13 \pm 0.06 \mathrm{pMC}$ was achieved down to a size of $150 \mu \mathrm{g} \mathrm{C}$, increasing to $0.28 \pm 0.11 \mathrm{pMC}$ at $30 \mu \mathrm{g} \mathrm{C}$ (Ertunç et al. 2005). Inherent background of the accelerator is negligible (Freeman et al. 2004a,b).

The magnitude of the contamination for AMS measurement depends on the mass of the carbon samples being processed. Combustion of acid-alkali-acid pretreated bituminous coal ranging from 100 to $500 \mu \mathrm{g} \mathrm{C}$ using routine methods (sealed quartz tube combustion with copper oxide, vacuum of $10^{-3}$ mbar) resulted in unsatisfactorily variable and high backgrounds $(2.3 \pm 1.4 \mathrm{pMC})$. While organic samples routinely submitted to our facility are generally $>1000 \mu \mathrm{g} \mathrm{C}$, different approaches to optimize sample combustion have been explored to extend our current sample size limit to meet the increasing demand for radiocarbon AMS analysis of small organic samples-e.g. combustion of isolated specific compounds.

As combustion tubes and copper oxide (Vogel et al. 1987; Kirner et al. 1995; De Neve et al. 1996; Vandeputte et al. 1998; Czernik and Goslar 2001) have been identified as sources of ${ }^{14} \mathrm{C}$ contamina-

\footnotetext{
'Natural Environment Research Council Radiocarbon Laboratory, Scottish Enterprise Technology Park, Rankine Avenue, East Kilbride G75 0QF, United Kingdom.

${ }^{2}$ Corresponding author. Email: T.Ertunc@nercrcl.gla.ac.uk.

${ }^{3}$ Scottish Universities Environmental Research Centre, Scottish Enterprise Technology Park, East Kilbride G75 0QF, United Kingdom.
}

(C) 2007 by the Arizona Board of Regents on behalf of the University of Arizona Proceedings of the 19 th International ${ }^{14} \mathrm{C}$ Conference, edited by $\mathrm{C}$ Bronk Ramsey and TFG Higham RADIOCARBON, Vol 49, Nr 2, 2007, p 271-280 
tion during combustion, the influence of different chemical reagents on the overall ${ }^{14} \mathrm{C}$ background level was considered. Alternatives to the established sealed-tube combustion method have been sought.

\section{EXPERIMENTAL SECTION AND RESULTS}

Figure 1 summarizes the experiments carried out, and the Appendix contains a detailed list of the components used.

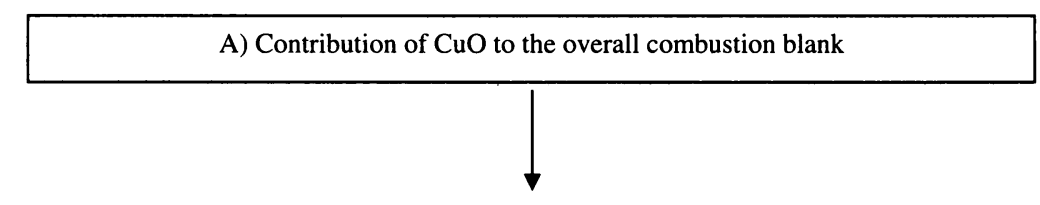

B) Modification of sealed-tube combustion to preclude contamination arising variable production batches of $\mathrm{CuO} \Rightarrow$ use of free $\mathrm{O}_{2}$ as an alternative

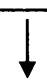

B1) Mass spec scans of free $\mathrm{O}_{2}$ to assess

B2) Combustion of bituminous coal to determine overall process blank of organic material $\mathrm{CO}_{2}$ contamination to determine

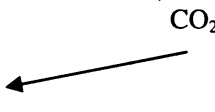

B3) Combustion of Iceland spar calcite mineral to differentiate between contamination arising from organic material and new combustion setup
B4) Combustion of IAEA-C5 to determine presence / absence of isotopic fractionation

Figure 1 Schematic overview of the individual experiments carried out to assess and differentiate sources of contamination during sample preparation and combustion.

\section{Graphitization and AMS Measurement}

$\mathrm{CO}_{2}$ was graphitized using $\mathrm{Fe} / \mathrm{Zn}$ reduction (Slota et al. 1987) on a preparation vacuum line previously described (Ertunç et al. 2005). The graphite targets were pressed into aluminium cathodes (National Electrostatics Corp.) using a constant pressure of 160 psi, backfilled with solid aluminium, and stored under argon until measurement. Targets were typically analyzed at currents of $20 \mu \mathrm{A}$, allowing simultaneous $\delta^{13} \mathrm{C}$ measurement $( \pm 1 \%$ ). Overall measurement precision of background-corrected and normalized data (given as percent modern carbon [pMC]) was 3-5\%o for sample masses $>100 \mu \mathrm{g} \mathrm{C}$, and 5-10\%o for masses $<100 \mu \mathrm{g} \mathrm{C}$. Background ratios were subtracted from the raw data before normalization with oxalic acid HOxII targets $>400 \mu \mathrm{g}$ C. Samples were analyzed together with similarly sized background samples. Samples $>100 \mu \mathrm{g} \mathrm{C}$ were analyzed until the required measurement precision (3-5\%o) was obtained. When target lifetime was limiting $(<100 \mu \mathrm{g} \mathrm{C})$, targets were analyzed until ${ }^{12} \mathrm{C}$ current was not available. For calculation of results, only runs showing stable beam characteristics of all 3 isotopes were used. Calculations of pMC were based on ${ }^{14} \mathrm{C} /{ }^{13} \mathrm{C}$ ratios, and the data were corrected to $-25 \delta^{13} \mathrm{C}_{\mathrm{VPDB}} \%$ o using AMS-measured $\delta^{13} \mathrm{C}$ values. 


\section{A) Contribution of CuO to the Overall Combustion Blank}

As $\mathrm{CuO}$ has previously been identified as a source of contamination (Vogel et al. 1987; Kirner et al. 1995; De Neve et al. 1997; Vandeputte et al. 1998; Czernik and Goslar 2001), CuO of different texture and purity from various suppliers was analyzed. One-mg $\mathrm{C}$ aliquots of $\mathrm{CO}_{2}$ were subsampled from large volumes of $\mathrm{CO}_{2}(2-4 \mathrm{~L})$ produced from Iceland spar calcite by hydrolysis, which had a characterized background of $0.13 \mathrm{pMC} \pm 0.06(n=14)$ (Ertunç et al. 2005). Quartz glass combustion tubes (12-mm end sealed), quartz glass inserts, silver foil, and $\mathrm{CuO}$ were cleaned at $900{ }^{\circ} \mathrm{C}$ for $5 \mathrm{hr}$ prior to sample combustion. After evacuating the quartz tube, aliquots of the $\mathrm{CO}_{2}$ were cryogenically transferred to the combustion tube, which was then sealed and combusted using the routine temperature program (Figure 2A). Table 1 summarizes the different types of $\mathrm{CuO}$ used and the overall blank values obtained.

\section{A) Combustion with $\mathrm{CuO}$}

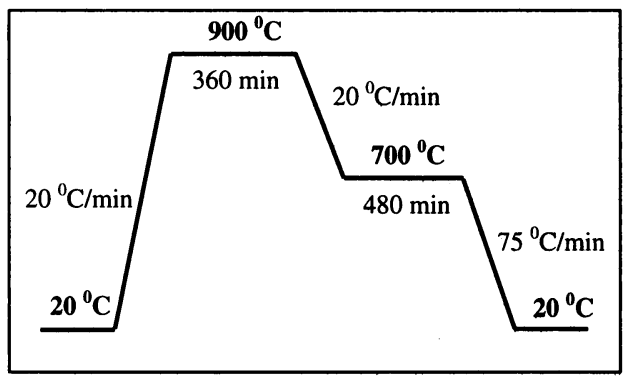

\section{B) Combustion with free $\mathrm{O}_{2}$}

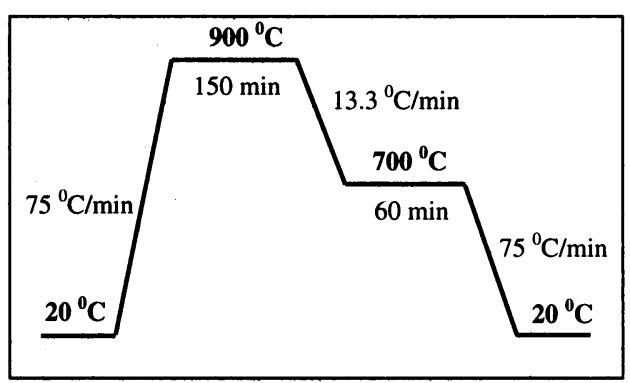

Figure 2 A) Temperature program routinely used for sealed-tube combustion of organic samples $>500 \mu \mathrm{g} \mathrm{C}$ with $\mathrm{CuO}$; B) modified temperature program for combustion of samples $<500 \mu \mathrm{g} \mathrm{C}$ with free $\mathrm{O}_{2}$.

Table 1 Different copper oxides tested as oxygen source for sealed-tube combustion; 1-mg C aliquots of large volume of ${ }^{14} \mathrm{C}$-free Iceland spar calcite have been used.

\begin{tabular}{lllll}
\hline $\mathrm{CuO}$ & Supplier & Texture & Purity $^{\mathrm{a}}$ & Overall $^{14} \mathrm{C}$ content in $\mathrm{pMC}^{\mathrm{b}}$ \\
\hline $\mathrm{CuO}^{\mathrm{c}}$ & Fisher Scientific & Wire Form & Technical grade & $0.12 \pm 0.01$ \\
$\mathrm{CuO} 2$ & $\mathrm{BDH}$ & Wire Form & Analytical grade & $0.16 \pm 0.04$ \\
$\mathrm{CuO3}$ & Fisher Scientific & Powder $(<100 \mu \mathrm{m})$ & Analytical grade & $0.28 \pm 0.07$ \\
$\mathrm{CuO} 4$ & Alfa Aesar & Powder $(<100 \mu \mathrm{m})$ & $99.995 \%$ & $0.19 \pm 0.03$ \\
$\mathrm{CuO5}$ & Alfa Aesar & Powder $(<100 \mu \mathrm{m})$ & ACS reagent & $0.18 \pm 0.04$ \\
$\mathrm{CuO6}$ & Alfa Aesar & Powder $(<100 \mu \mathrm{m})$ & $99.9999 \%$ & $0.25 \pm 0.07$ \\
\hline
\end{tabular}

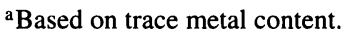

${ }^{b} \mathrm{pMC}=$ percent modern carbon; mean value of 3 measurements with $1-\sigma$ error of arithmetic mean.

${ }^{\mathrm{c}}$ Routine oxidizing reagent.

$\mathrm{CuO1}$, which is routinely used for sealed-tube combustion of samples $>500 \mu \mathrm{g} \mathrm{C}$, resulted in blank values of $0.12 \pm 0.1 \mathrm{pMC}$. Increasing the $\mathrm{CuO}$ purity from technical (CuO1) to analytical grade $(\mathrm{CuO} 2)$ did not result in improved blank values, which were within 1- $\sigma$ error of those for CuO1. All fine-powdered $\mathrm{CuO}(\mathrm{CuO} 3$ to $\mathrm{CuO} 6)$ showed similar or elevated blank values compared with $\mathrm{CuO} 1$. A higher supplier-quoted analytical purity of the copper oxide did not consistently produce lower blank values, probably because the analytical purity is based on trace metal content. The lowest value, obtained with $\mathrm{CuO} 1$, is nearly $3 \times$ lower than values obtained by combustion of comparable amounts of bituminous coal $(0.32 \pm 0.1 \mathrm{pMC})$. The additional contamination seems to be introduced by the organic sample material itself, possibly by surface adsorption of atmospheric $\mathrm{CO}_{2}$. Typical 
values for combustion of graphite/coal samples range from 50 to $60 \mathrm{kyr}(0.20-0.06 \mathrm{pMC})$ (Kirner et al. 1995). Storing graphite under argon after pretreatment has resulted in values as low as $69 \mathrm{kyr}$ (0.02 pMC), whereas samples stored in air have shown higher values of 58-60 kyr (0.07-0.06 pMC) (Schmidt et al. 1987). As our pretreated bituminous coal had not been stored under argon, contamination by contemporary $\mathrm{CO}_{2}$ is plausible. A vacuum of $10^{-3}$ mbar during evacuation of the quartz combustion tube may have been insufficient to completely remove $\mathrm{CO}_{2}$ adsorbed to the sample.

\section{B) Modification of Sealed-Tube Combustion}

Although $\mathrm{CuO} 1$ produced acceptably low backgrounds, we also wanted to investigate the use of pure oxygen as an alternative oxidant, e.g. for use in stepped-combustion techniques and combustion of isolated chemical compounds. A lecture bottle containing oxygen ( $99.999 \%$ purity) was attached to the manifold of a dedicated vacuum line via a $1 / 4$-inch tube compression fitting. A consistent minimum vacuum of $2 \times 10^{-5}$ mbar was achieved with an oil-free scroll pump and a turbomolecular pump (BOC Edwards) (Ertunç et al. 2005). The design of the modified combustion method was chosen to meet a future objective, i.e. that sample tubes could be connected directly to a GC-fraction collector, thus limiting sample transfer and introduction of contaminant carbon. Highpurity oxygen was used, and purity was checked by mass spectrometry. The initial challenge was to find a valve that was sufficiently leak-tight and chemically inert when exposed to free $\mathrm{O}_{2}$. Design A (Figure 3) used Kimble-Kontes ${ }^{\circledR}$ valves. Designs B and C included modifications using metal Swagelok ${ }^{\circledR}$ valves to prevent Viton ${ }^{\circledR} \mathrm{O}$-rings from being exposed to free $\mathrm{O}_{2}$. The combustion procedure was as follows:

- a) Instead of flame-sealing both ends of the quartz glass tube, the 12-mm end was sealed and closed with a valve at the 6-mm end. The tube was partly inserted into a tube furnace, with the valve remaining outside.

- b) As free $\mathrm{O}_{2}$ was used, combustion times were reduced compared to routine methods: combustion at $900^{\circ} \mathrm{C}$ from 6 to $2.5 \mathrm{hr}$; and dwell time at $700^{\circ} \mathrm{C}$ from 8 to $1 \mathrm{hr}$ (Figure 2B).

$\mathbf{A}$

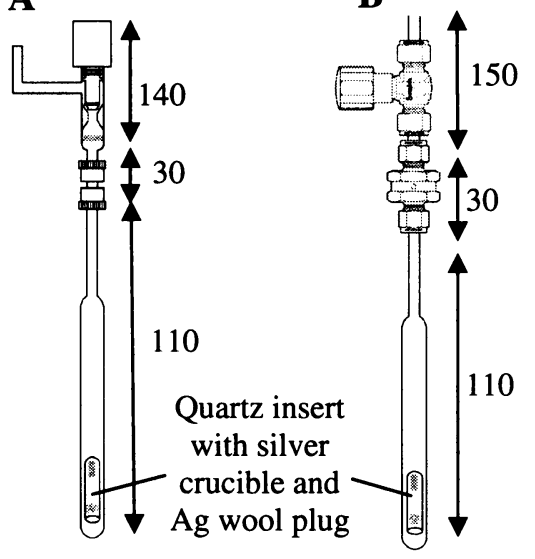

C

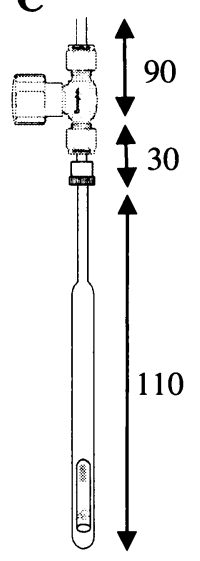

Figure 3 Schematic diagram of different combustion vessels used; A and $\mathrm{B}$ show the initial setup, $\mathrm{C}$ shows the finalized design for combustion of small organic samples $<1 \mathrm{mg} \mathrm{C}$ with free $\mathrm{O}_{2}$; outer diameters of lower and upper parts of combustion tubes are 12 and $6 \mathrm{~mm}$, respectively. The 6-mm neck of the combustion tube of design $C$ is plugged with a clean silver wool, whereas a glass frit is used in A. Detailed specification of valves and fittings can be found in the Appendix. 
Glassware and silver were cleaned for $5 \mathrm{hr}$ at $900{ }^{\circ} \mathrm{C}$. Limiting the maximum sample mass to $1 \mathrm{mg}$ carbon and approximately $3 \mathrm{~mL}$ free $\mathrm{O}_{2}$ (equivalent to 134 nmole $\mathrm{O}_{2}$ or one third of the total vessel volume) ensured complete combustion. The different designs $A$ to $C$ (Figure 3 ) illustrate the filters chosen to avoid contamination of the vacuum line from particulates: A) $3-\mu \mathrm{m}$ glass frit; B) sintered $2-\mu \mathrm{m}$ metal filter (baked at $450^{\circ} \mathrm{C}$ for $5 \mathrm{hr}$ prior to use); C) silver wool plug cleaned for $5 \mathrm{hr}$ at $900{ }^{\circ} \mathrm{C}$. The following assessment criteria were used: a) retention of vacuum; b) contamination from the valve and/or filter unit during heating in the presence of free oxygen.

\section{B1) Design of Sample Combustion Vessel}

To provide a baseline estimate of any $\mathrm{CO}_{2}$ in the high-purity oxygen and to qualitatively assess carbon contamination during subsequent combustion, we used stable isotope mass spectrometry (IRMS; VG Optima dual-inlet mass spectrometer). The relative sizes of the peaks at a mass-tocharge ratio $(\mathrm{m} / \mathrm{z})$ of $16\left(\mathrm{O}_{2}\right)$ and $45\left(\mathrm{CO}_{2}\right)$ were used as qualitative indicator of carbon contamination. Three $\mathrm{mL}$ of $\mathrm{O}_{2}$ were filled into the different combustion tubes (Figures 3A-C) and scanned without combustion after leaving the oxygen in the vessels for $5 \mathrm{hr}$ (equivalent to time of full combustion cycle, see Figure 2B). A further set of gas aliquots was scanned for $\mathrm{m} / \mathrm{z} 45$ after combustion (Figures 4B-D). The scan was performed by varying the magnet current (Figure 4).

\section{A) Oxygen in lecture bottle (not heated, design A-C)}

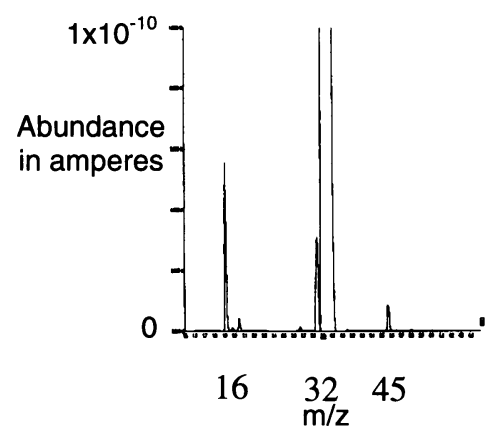

B) Oxygen after heating; Kontes ${ }^{\circledR}$ valve with glass frit (design $A$ )

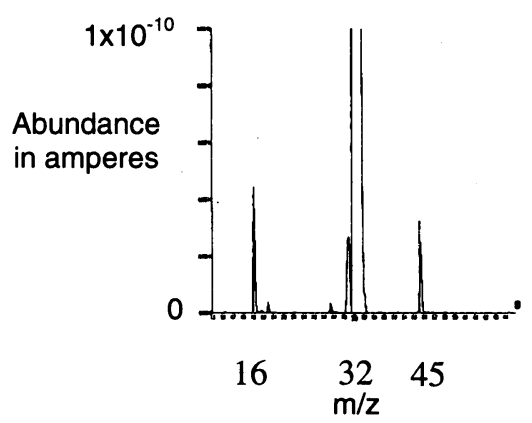

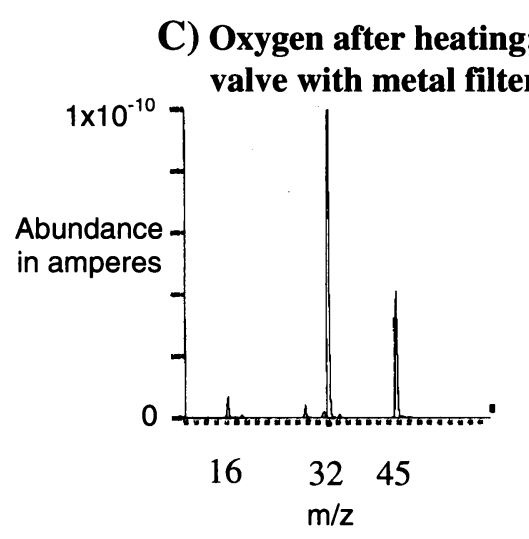

D) Oxygen after heating; Swagelok ${ }^{\circledR}$ valve with Ag-plug (design C)

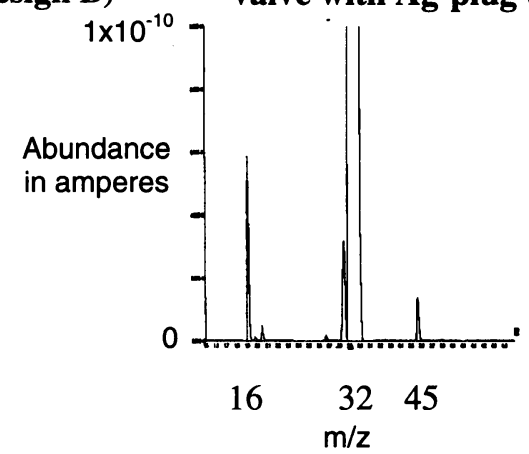

Figure 4 Mass spectrometry analysis (VG Optima, dual-inlet mass spectrometer) of oxygen before (A) and after heating (B-D) in combustion tubes. 
Pure oxygen directly taken from the lecture bottle shows a very small $\mathrm{m} / \mathrm{z} 45$ peak as compared to $\mathrm{m} / \mathrm{z} 16$, indicating relatively small amounts of $\mathrm{CO}_{2}$ (Figure 4A). Passing the $\mathrm{O}_{2}$ through a molecular sieve filter prior to use did not reduce the ratio of $\mathrm{m} / \mathrm{z} 45$ to 16 . This could be observed for all different designs of combustion vessel (Figure 4A). Heating pure $\mathrm{O}_{2}$ in a combustion tube closed with a Kontes ${ }^{\circledR}$ valve resulted in an increased $\mathrm{CO}_{2} / \mathrm{O}_{2}$ ratio, suggesting the formation of $\mathrm{CO}_{2}$ from carbon residues in the valve during combustion, possibly adsorbed carbon on O-rings and/or the glass filter (Figure 3A). To avoid exposure of O-rings to free oxygen, stainless-steel Swagelok ${ }^{\circledR}$ valves with metal filter units (Figure 3B) were tested: a significantly elevated signal ratio of $\mathrm{m} / \mathrm{z} 45 \mathrm{to} \mathrm{m} / \mathrm{z} 16$ (Figure 4C) indicated contamination with extraneous carbon. Although the metal filter had been cleaned by heating prior to use, the high surface area may have retained adsorbed carbon, released as $\mathrm{CO}_{2}$ during combustion with oxygen. The filter unit was removed and replaced by a cleaned plug of silver wool (Figure 3C). The ratio of $\mathrm{m} / \mathrm{z} 45$ to 16 (Figure 4D) was similar to that of pure bottled $\mathrm{O}_{2}$. The results obtained were confirmed by AMS analysis of organic blank targets: $1 \mathrm{mg} \mathrm{C}$ of bituminous coal was combusted with $3 \mathrm{~mL}$ free $\mathrm{O}_{2}$ in the different tube designs, graphitized, and analyzed by AMS. Measurements were carried out in triplicate. Results obtained (Figure 3 ) were $0.35 \pm$ $0.01 \mathrm{pMC}$ (design A); $0.99 \pm 0.01 \mathrm{pMC}$ (design B); and $0.14 \pm 0.04 \mathrm{pMC}$ (design C). Based on these results, combustion tube design $C$ was considered to be optimal and has been used in all subsequent experiments.

\section{B2) Combustion of Bituminous Coal with Free Oxygen Using Combustion Vessel Design C}

The $\mathrm{CO}_{2}$ was produced from acid-alkali-acid pretreated bituminous coal by combusting the material with $3 \mathrm{~mL}$ of oxygen in combustion vessel design $\mathrm{C}$ (Figure $3 \mathrm{C}$ ). To overcome the static charge of the quartz insert, sample material was weighed into silver crucibles and placed into the insert, which was then plugged with clean silver wool. Graphite targets ranging from 80 to $1000 \mu \mathrm{g} \mathrm{C}$ were analyzed by AMS (Figures 5A and B).
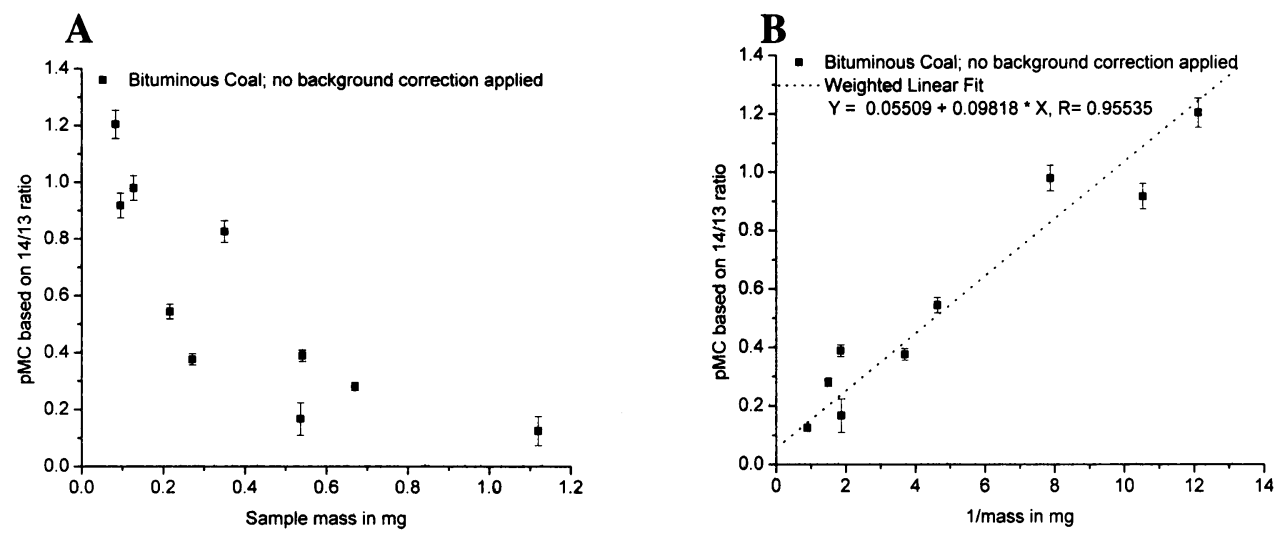

Figure 5 A) ${ }^{14} \mathrm{C}$ activity expressed as pMC based on 14/13 ratio versus carbon content in AMS target; B) pMC based on 14/13 ratio versus inverse carbon mass in target. Data points obtained by individual combustion of small amounts of acid-alkali-acid pretreated bituminous coal; isotopic ratios were corrected for AMS-measured $\delta^{13} \mathrm{C}$ and normalized to the corresponding averaged value of $\mathrm{HOxII}>400 \mu \mathrm{g} \mathrm{C}$; no procedural blank correction was applied. Error bars express $1-\sigma$ confidence limit.

We observed similar trends in background values to published values (Donahue et al. 1997; Pearson et al. 1998; Czernik and Goslar 2001; Hua et al. 2001). As described in Donahue et al. (1997), we also observed an increase of background levels below $1 \mathrm{mg} \mathrm{C}$ from $0.13 \pm 0.05$ to $1.20 \pm 0.04 \mathrm{pMC}$ 
( $80 \mu \mathrm{g} \mathrm{C})$, showing a clear inverse mass dependency. On the assumption that the contaminant carbon is modern, every target, independent of its mass, would be contaminated with roughly $1 \mu \mathrm{g} \mathrm{C}$. This was confirmed by the linear fit obtained when plotting the ${ }^{14} \mathrm{C}$ activity against the inverse target mass (Figure 5B). Other combinations of contaminant mass and activity have also been reported (Brown and Southon 1997; Hua et al. 2001).

\section{B3) Combustion of Iceland Spar Calcite with Free Oxygen and Copper Oxide}

To examine the possibility of ${ }^{14} \mathrm{C}$ contamination due to adsorption of atmospheric $\mathrm{CO}_{2}$ by bituminous coal, 30 to $350 \mu \mathrm{g} \mathrm{C}$ of Iceland spar calcite mineral (HCl-etched) was combusted (Reller 1988) with $3 \mathrm{~mL}$ of free oxygen and copper oxide $(500 \mathrm{mg})$, respectively. The mineral was placed wet into the combustion tube after etching and immediately evacuated.

Results obtained are shown in Figure 6A and B. There is no significant difference between combustion with $\mathrm{CuO}$ or free oxygen (Figure 6A). Both data sets are therefore combined to plot a linear regression of pMC against 1/sample mass, showing an inverse mass dependency for targets $<200 \mu \mathrm{g} \mathrm{C}$ (Figure 6B). Background levels increase from $0.15 \pm 0.02 \mathrm{pMC}(360 \mu \mathrm{g} \mathrm{C})$ to $1.30 \pm$ $0.10 \mathrm{pMC}(30 \mu \mathrm{g} \mathrm{C})$ (Figure 6B). Values for target masses $>200 \mu \mathrm{g} \mathrm{C}$ seem to be rather constant around an average value of $0.19 \pm 0.08 \mathrm{pMC}(n=3)$ (Figure 6A). Apparently, a portion of contaminant $C$ detected in the coal samples had been introduced during the sample handling prior to combustion, as it was exposed to the atmosphere, whereas the Iceland spar calcite mineral was acidetched to remove any adsorbed $\mathrm{CO}_{2}$ and immediately transferred to the combustion tube. The remaining fixed amount of extraneous carbon detected by combusting Iceland spar calcite is probably due to adsorbed $\mathrm{CO}_{2}$ in the combustion vessel, including the valve used. Despite the small constant amount of introduced contaminant carbon (roughly $0.5 \mu \mathrm{g} \mathrm{C}$ based on the assumption that the contamination is modern), the modified combustion method was considered much more suitable for the analysis of small organic samples than the laboratory's routine method.
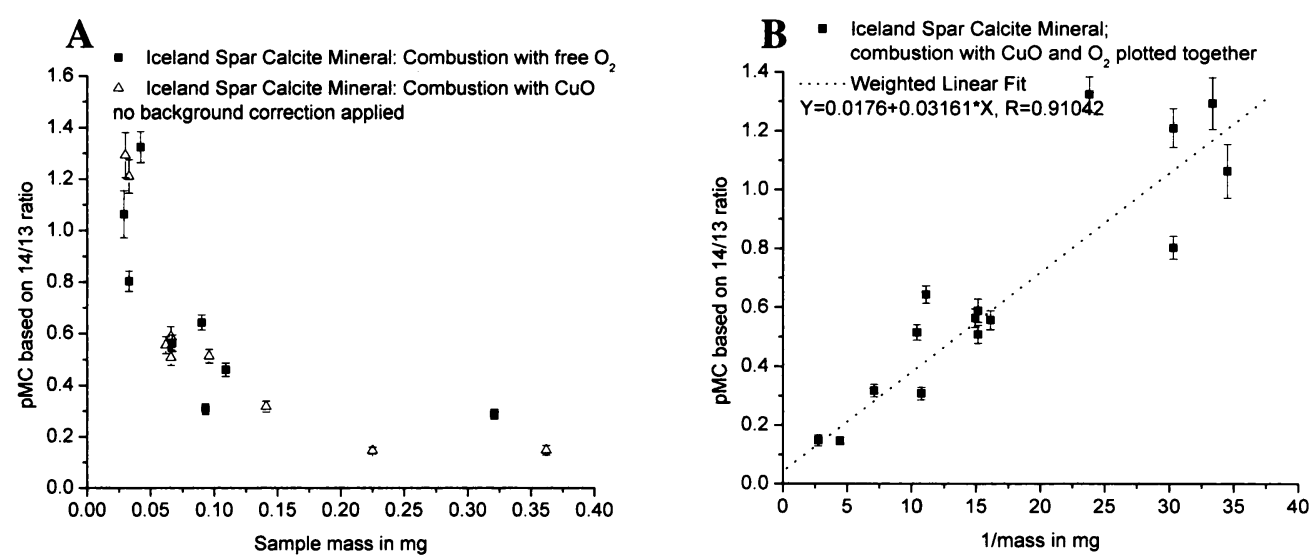

Figure 6 A) ${ }^{14} \mathrm{C}$ activity expressed as pMC based on $14 / 13$ ratio versus carbon content in AMS target; B) pMC based on 14/13 ratio versus inverse carbon mass in target. Data points obtained by individual combustion of small amounts of Iceland spar calcite mineral with $\mathrm{CuO}$ and $\mathrm{O}_{2}$; isotopic ratios were corrected for AMS-measured $\delta^{13} \mathrm{C}$ and normalized to the corresponding averaged value of $\mathrm{HOxII}>400 \mu \mathrm{g} \mathrm{C}$; no procedural blank correction was applied. Error bars express $1-\sigma$ confidence limit. 


\section{B4) Combustion of Known-Age Standard with Free Oxygen}

Two Creeks Wood standard IAEA-C5 (consensus value 23.05 pMC) was combusted with free oxygen as described above. Targets ranging from 40 to $1000 \mu \mathrm{g} \mathrm{C}$ were analyzed by AMS.

The preceding experiments described above were carried out to determine the optimum combustion conditions. Using design $\mathrm{C}$ (Figure 3C), free oxygen, and background corrections appropriate for different carbon masses, we could confirm that down to $55 \mu \mathrm{g} \mathrm{C}$ the results for IAEA-C5 were within $2 \sigma$ of the reported consensus value of 23.05 pMC (Figure 7) (Zeisler et al. 1995-1996).

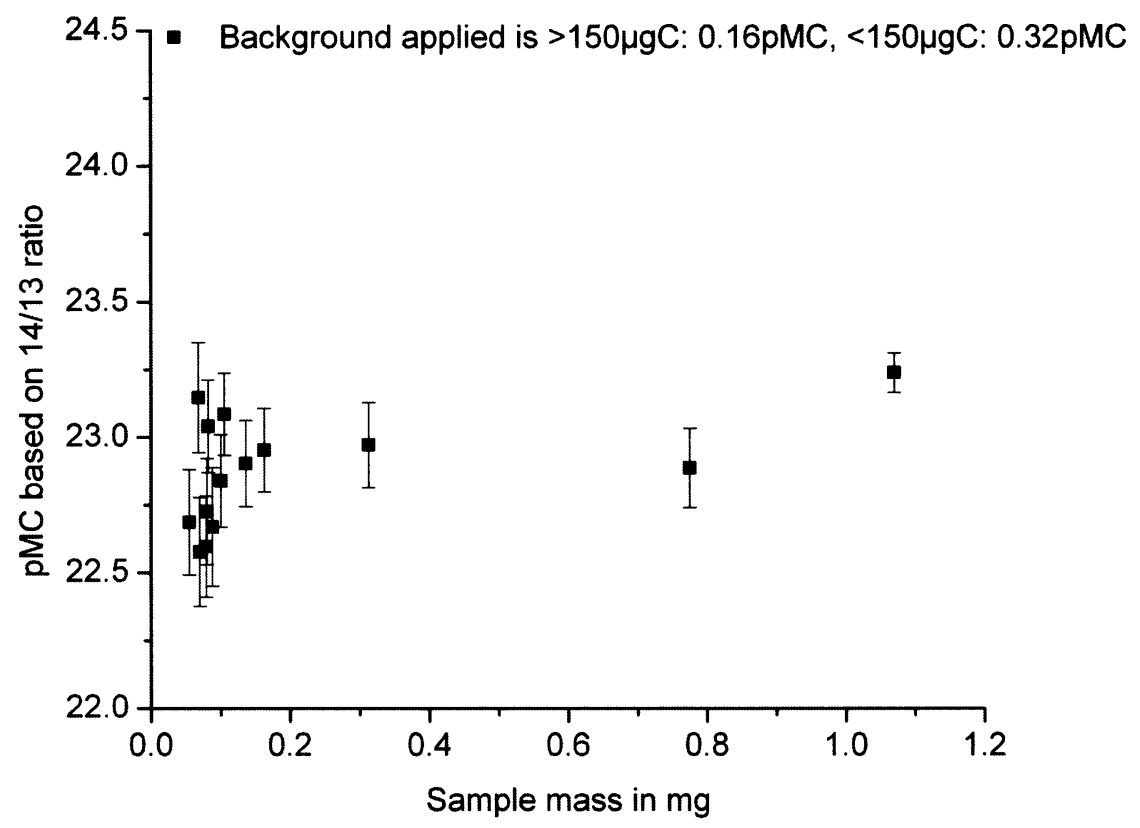

Figure $7{ }^{14} \mathrm{C}$ activity expressed as pMC based on ${ }^{14} \mathrm{C} /{ }^{13} \mathrm{C}$ ratios of graphite targets obtained by individual combustion of IAEA-C5. Isotopic ratios were corrected for AMS-measured $\delta^{13} \mathrm{C}$ and normalized to the corresponding averaged value of HOxII $>400 \mu \mathrm{g} \mathrm{C}$; procedural blank correction was applied (Ertunç et al. 2005). Error bars express 1- $\sigma$ confidence limit.

\section{CONCLUSION}

This study addresses part of a larger objective to determine the minimum size of inorganic and organic samples that can reliably be analyzed as graphite targets and to differentiate between contamination arising from sample preparation and graphitization. We focused on improving the laboratory's procedural blank for organic samples to accommodate the increasing demand for smallsample analysis. Routinely used copper oxide contributes $0.12 \pm 0.1 \mathrm{pMC}$ to the overall process blank using the routine sealed-tube combustion method and gas aliquots subsampled from large volumes of $\mathrm{CO}_{2}$ produced from Iceland spar calcite by hydrolysis, but combustion of bituminous coal with the same amount of carbon and using identical methods resulted in values almost $3 \times$ higher. We attribute this to exposure of the bituminous coal to atmosphere prior to combustion. Storing the coal and other small organic samples under argon in a gas-tight container may help to minimize contamination by adsorbed $\mathrm{CO}_{2}$. Analysis of different types of copper oxide showed that higher analytical purity does not necessarily result in improved blank values. Consequently, each new batch of oxide should be tested for extraneous ${ }^{14} \mathrm{C}$ contamination. Sample combustion was modified from the 
sealed-tube combustion method to using free $\mathrm{O}_{2}$ as an oxidant to accommodate future sample preparation by gas chromatography (GC) and stepped-combustion techniques. Using this modified procedure, satisfactory low and stable background levels of $0.13 \pm 0.1 \mathrm{pMC}$ for $>1-\mathrm{mg} \mathrm{C}$ targets can now be obtained. This can mainly be attributed to a much lower vacuum on the new vacuum line (Ertunç et al. 2005). Smaller masses $(<1 \mathrm{mg} \mathrm{C}$ ) follow a strict inverse mass dependency down to the smallest mass analyzed of $80 \mu \mathrm{g} \mathrm{C}$, resulting in a ${ }^{14} \mathrm{C}$ activity of $1.2 \pm 0.05 \mathrm{pMC}$. The new setup is considered suitable for combustion of samples ranging from 100 to $500 \mu \mathrm{g} \mathrm{C}$, and results are encouraging in that a better detection limit should be possible with pure compounds collected from the gas chromatograph as they will not be exposed to any atmosphere.

As measurement uncertainty and scatter increases dramatically below $100 \mu \mathrm{g} \mathrm{C}$, we currently recommend allowing a precision of up to $5 \%$ for known-age samples of $\sim 12,000{ }^{14} \mathrm{C}$ yr below $100 \mu \mathrm{g} \mathrm{C}$ and set a detection limit of at least $1.5 \pm 0.1 \mathrm{pMC}$ for samples close to background values at a sample mass of $\sim 100 \mu \mathrm{g} \mathrm{C}$. The detection limit for targets ranging from $500 \mu \mathrm{g}$ to $1000 \mu \mathrm{g} \mathrm{C}$ is $46 \mathrm{kyr}$ and $33 \mathrm{kyr}$ below $100 \mu \mathrm{g} \mathrm{C}$. To extend the ${ }^{14} \mathrm{C}$ detection limit beyond these values, further improvements are still necessary, especially if the organic material is highly adsorptive and likely to be contaminated with atmospheric $\mathrm{CO}_{2}$. We currently do not routinely analyze small organic samples $<100 \mu \mathrm{g} \mathrm{C}$.

\section{REFERENCES}

Brown TA, Southon JR. 1997. Corrections for contamination background in AMS ${ }^{14} \mathrm{C}$ measurements. $\mathrm{Nu}$ clear Instruments and Methods in Physics Research B 123(1-4):208-13.

Czernik J, Goslar T. 2001. Preparation of graphite targets in the Gliwice radiocarbon laboratory for AMS ${ }^{14} \mathrm{C}$ dating. Radiocarbon 43(2A):283-91.

De Neve K, Strijckmans K, Vandeputte K, Dams R. 1997. Deuteron activation analysis for the determination of carbon in iron and copper oxide, reagents for ${ }^{14} \mathrm{C}$-dating by accelerator mass spectrometry. Journal of Radioanalytical and Nuclear Chemistry 221(1-2): 79-83.

Donahue DJ, Beck JW, Biddulph D, Burr GS, Courtney C, Damon PE, Hatheway AL, Hewitt L, Jull AJT, Lange T, Lifton N, Maddock R, McHargue LR, O'Malley JM, Toolin LJ. 1997. Status of the NSF-Arizona AMS laboratory. Nuclear Instruments and Methods in Physics Research B 123(1-4):51-6.

Ertunç T, Xu S, Bryant CL, Maden C, Murray C, Currie M, Freeman SPHT. 2005. Progress in AMS target production of sub-milligram samples at the NERC Radiocarbon Laboratory. Radiocarbon 47(3):453-64.

Freeman S, Bishop P, Bryant C, Cook G, Fallick A, Harkness D, Metcalfe S, Scott M, Scott R, Summerfield M. 2004a. A new environmental sciences AMS laboratory in Scotland. Nuclear Instruments and Methods in Physics Research B 223-24:31-4.

Freeman S, Xu S, Schnabel C, Dougans A, Tait A, Kitchen R, Klody G, Loger R, Pollock T, Schroeder J, Sunquist M. 2004b. Initial measurements with the SUERC accelerator mass spectrometer. Nuclear Instruments and Methods in Physics Research B 223-24:
195-8.

Hua Q, Jacobsen GE, Zoppi U, Lawson EM, Williams AA, Smith AM, McGann MJ. 2001. Progress in radiocarbon target preparation at the ANTARES AMS Centre. Radiocarbon 43(2A):275-82.

Kirner DL, Taylor RE, Southon JR. 1995. Reduction in backgrounds of microsamples for AMS ${ }^{14} \mathrm{C}$ dating. Radiocarbon 37(2):697-704.

Pearson A, McNichol AP, Schneider RJ, von Reden KF, Zheng Y. 1998. Microscale ${ }^{14} \mathrm{C}$ measurement at NOSAMS. Radiocarbon 40(1):61-75.

Reller A. 1988. Carbon dioxide as mediating compound between organic and inorganic matter. Chimia 42(3): 87-90.

Schmidt FH, Balsley DR, Leach DD. 1987. Early expectations of AMS: greater ages and tiny fractions. One failure? - One success. Nuclear Instruments and Methods in Physics Research B 29(1-2):97-9.

Slota Jr PJ, Jull AJT, Linick TW, Toolin LJ. 1987. Preparation of small samples for ${ }^{14} \mathrm{C}$ accelerator targets by catalytic reduction of CO. Radiocarbon 29(2):303-6.

Vandeputte K, Moens L, Dams R, van der Plicht J. 1998. Study of the ${ }^{14} \mathrm{C}$-contamination potential of $\mathrm{C}$-impurities in $\mathrm{CuO}$ and Fe. Radiocarbon 40(1):103-10.

Vogel JS, Nelson DE, Southon JR. 1987. ${ }^{14} \mathrm{C}$ background levels in an accelerator mass spectrometer system. $R a$ diocarbon 29(3):323-33.

Zeisler R, Stone SF, Parr RM, Bel-Amakeletch T. 19951996. Survey of reference materials. Vienna: International Atomic Energy Agency (IAEA). IAEA-TECDOC-854 [Volume 1] and IAEA-TECDOC-880 [Volume 2]. 


\section{APPENDIX}

Components used in A, see Figure 1.

$\begin{array}{ll}\begin{array}{l}\text { Combustion tubes } \\ \text { Inserts }\end{array} & \text { Multi-lab; quartz glass, } 12 \text { and } 6 \mathrm{~mm} \text { OD, overall length } 270 \mathrm{~mm} . \\ \text { Copper oxide } & \text { Multi-lab; 6-mm quartz glass, } 20 \mathrm{~mm} \text { length, sealed at one end. } \\ & \begin{array}{c}\text { Fisher Scientific, BDH, Alfa Aesar } \\ \text { technical grade to } 99.999 \% \text { wire form and powder ranging from }\end{array} \\ \text { tilver foil } & \begin{array}{c}\text { Alfa Aesar; } 0.25 \mathrm{~mm} \text { thickness, annealed, } 99.998 \% \text { purity based on trace } \\ \text { metal content. }\end{array} \\ \text { Tube furnace } & \text { Carbolite }^{\circledR} \text {; with ceramic inserts. }\end{array}$

Components used in B1-B4, see Figure 1.

\begin{tabular}{|c|c|}
\hline Combustion tubes & Multi-lab; quartz glass, 12 and $6 \mathrm{~mm} \mathrm{OD}$, overall length of $160 \mathrm{~mm}$. \\
\hline Valves & $\begin{array}{l}\text { VWR, Kimble-Kontes HI-VAC }{ }^{\circledR} \text { with } 3-\mu \text { m glass frit; Swagelok }{ }^{\circledR} \text { Whitey } \\
\text { "D" series and } 2-\mu \mathrm{m} \text { FW-series filter with } 2-\mu \mathrm{m} \text { sintered element. }\end{array}$ \\
\hline Fittings & $\begin{array}{l}\text { South Scotland Valve \& Fitting Co. Ltd., Swagelok Ultra-Torr vacuum } \\
\text { fittings with fluorocarbon FCM O-ring; } 1 / 4 \text {-inch tube compression fitting. }\end{array}$ \\
\hline Oxygen & CK Gases; $99.999 \%$ purity in 50-L lecture bottle. \\
\hline Regulator & $\begin{array}{l}\text { CK Gases; Concoa Model 312-3322 CGA } 180 \text { with diaphragm valve and } \\
\text { 1/4-inch compression fitting. }\end{array}$ \\
\hline Furnaces & Carbolite single-tube furnace; ID $20 \mathrm{~mm}$. \\
\hline Silver foil & $\begin{array}{l}\text { Alfa Aesar; } 0.25-\mathrm{mm} \text { thickness, annealed, } 99.998 \% \text { purity based on trace } \\
\text { metal content. }\end{array}$ \\
\hline Silver wool & Alfa Aesar; $99.9 \%+$, purity based on trace metal content. \\
\hline
\end{tabular}

